\title{
Research on the Innovative Development of Interdisciplinary Talent Training for University Students in the Integration of Community Group Buying and New Rural Logistics*
}

\author{
Jiali $\mathrm{Zhu}^{1}$ Rouhua Wang ${ }^{1, * *}$ \\ ${ }^{l}$ Foreign Language School, Changchun Institute of Technology, Changchun, Jilin, China \\ ${ }^{* * *}$ Corresponding author. Email: wrhwin@163.com
}

\begin{abstract}
This paper is the stage result of a study on the innovative development of college students who are instructed by teachers to participate in interdisciplinary integration. In the area of interdisciplinary talent training for foreign language majors in higher education institutions, Changchun Institute of Technology has incorporated a core course in logistics management - Logistics. The study of this course has led to a great interest in interdisciplinary integration. The interdisciplinary training students have not only participated in the innovation development related competitions and achieved good results, but also the teachers and students have jointly conducted theoretical and practical research on the integration model of community group purchase and new rural logistics. This paper proposes a new model of integration of community group purchase and new rural logistics: two-way — double network - double platform "ecological logistics". The future application of this model is a useful support to the rural revitalization of China.
\end{abstract}

Keywords: Interdisciplinary integration, Innovation development of university students, Community group buying, Logistics model.

\section{INTRODUCTION}

In recent years, under the leadership of the Party and the State, China's war against poverty has been remarkable, but each rural area has a different starting point and naturally different economic development. Today, with such advanced technology, some areas still cannot enjoy the convenience brought by technology and enjoyable consumption.

Nowadays, China's urbanization development and agricultural modernization receive a strong push. Rural and urban areas have become more prominent as bridges linking urban and rural areas, connecting industry and agriculture, and undertaking two-way logistics. Under the pressure conditions of industrial upgrading, high cost, space constraint and traffic congestion, urban logistics is

*Fund: This paper is supported by the following provincial and university level funds under the project number: 202111437111, S202111431749 promoted to the high-end direction of platform development on the one hand, and the physical logistics industry is promoted to move outward on the other. While rural logistics in the lack of effective factor support and logistics infrastructure support, began to seek upward to build a new rural logistics platform with richer resources and closer to the market. In addition, the development of Internet economy promotes the separation of physical space and virtual space, so that the new rural logistics is free from the traditional restrictions such as geographical location, market distance and resource barriers and gives full play to local advantages, which promotes the reconstruction of new rural logistics form and logistics space, thus truly forming a new urbanrural circulation system that integrates community group purchase and new rural logistics. In this realistic background, this paper selects community group purchase and new rural logistics as the key 
research object with more important practical significance.

This paper aims to use the integration of community group buying and new rural logistics to make it easier for rural people to integrate into the pace of the new era, thus improving the standard of living and at the same time raising consumption levels and promoting economic development. The development of the integration of community group buying and new rural logistics model can also be used to sell and spread some of the rural products and special culture outward.

\section{RESEARCH CONTENTS}

In order to reveal the changing role and status of new rural logistics in the development of the times, this paper starts from the investigation and research of the current situation of new rural logistics system, constructs a new rural logistics ecosystem model through comparative analysis method, and explores the feasibility of integrating community group purchasing into new rural logistics. Through the mature theoretical approaches such as system theory [1], population ecology theory [2] and evolutionary game theory [3], this paper studies and analyzes the ecological evolutionary direction, evolutionary path and evolutionary mechanism of the new rural logistics system with a view to integrating the new purchase concept of community group purchasing into it. The platform construction is carried out through system dynamics simulation [4] thus testing this model. As a result of this paper, the research includes the following three innovative results.

In this paper, a new rural logistics ecosystem model of "community group purchase and new rural eco-logistics double-layer circle" is constructed through various ways of research. The model integrates community group purchase into the core elements of new rural logistics, new rural logistics support elements and new rural logistics environment elements. Material flow, capital flow, technology flow and personnel flow generate four types of ecological flow [5]. It forms two layers of "chain-loop-function" as the basic layer and "platform-module" as the leading layer. Among them, the platform is in the top layer, the modules are dynamically combined into a flexible chain [6], and the functions are integrated in the platform and the modular flexible chain. At the same time, this model is also a new rural logistics ecosystem composed of "platform-module".
This paper combines ecological theory and system theory research to reveal the mechanism, path and direction of the ecological evolution of new rural logistics. Among them, the ecological element changes of three types of subject elements are the basis of evolution: technology dependence, system dependence and relationship dependence are the equilibrium evolution paths; ecological flow is the driving mechanism for the evolution of new rural logistics; symbiotic mechanism and competition mechanism cause ecological position changes as the transmission mechanism of evolution; "integration-synergy" is the amplification mechanism of evolution. The evolution of the model from "chain-function" to "platform-module" is the evolutionary direction of integrating community group purchase into the new rural logistics ecosystem.

An important management insight can be drawn from the research content of this paper, "two-way — double network - two-layer platform" is the evolutionary model of urban-rural integrated logistics ecosystem [7]. The two-way logistics combined with the regionalized division of labor brings about a large circulation, forming two market networks in rural and urban areas. Rural logistics is looking for resource advantages and market advantages to build a logistics platform upwards. As a result of the two forces, the top-level virtual platform of urbanization and the physical logistics platform of village-based are no longer separated, forming a new rural logistics and community group purchase integration mode of "two-way - double network — double platform", and the platform and network are connected by modern "collection and delivery/distribution" [8]. The platform and the network are connected through a modern "set delivery/distribution" [8].

This paper at this stage has been through the creation of a new community group purchase and the integration of new rural logistics model, through the establishment of the WeChat public way to the initial model test. The community group purchase will be sunk to the rural areas, collect the contact information of the wholesalers of various products, collect the product information well and carefully selected and marketed to the surrounding rural areas, only raising the factory price of the products a little, earning small profits and selling more, and then analyze the data according to the needs of the pilot rural areas to lay the foundation for the future purchase ratio. At the same time, we found that the characteristics of the rural areas will be unique to the rural areas but due to sales 
methods and lagging products sold in the same way, and even the rural characteristics of the culture in the platform sales and dissemination, while in each rural area, to find local people for training, as the head of the position, to the village name of the sale of goods and explain, at the beginning of the sale, the products sold to buy and send marketing methods, through the direct experience of the villagers, this product The product is advertised free of charge, and a small portion of the original advertising cost of the product is taken to benefit the villagers. By establishing the commercial image of this product, the free advertising is achieved through the villagers' population, and a lot of material and financial resources are saved. At the same time, we set up a special section for information feedback, and for false goods or shoddy goods, we adopt the way of triple compensation for reporting, and give a reward system to the head of excellent performance to actively encourage villagers to join, and gradually expand the scope later, not only limited to daily necessities. At the same time and the logistics company cooperation, recruiting local people in the major villages between the delivery, while can solve the problem of rural labor outflow to a certain extent.

\section{RESEARCH BACKGROUND AND DEVELOPMENT DYNAMICS}

\subsection{Research Background}

Today, with the increasingly high cost of online traffic, the "community group purchase" model is emerging with low comprehensive costs, traffic dividends and mutual trust between neighbors. The mainstream model of community group purchase: community as the node, online community establishment, offline delivery, the platform provides supply chain, logistics and warehousing and after-sales support. Now in the community group buying market, the mainstream view is that the current model is not mature enough due to the relatively low threshold of community group buying business. Therefore, this track will face huge risks in the future, and these risks will be harvested by a large amount of capital. The entry of large enterprises and huge investment may accelerate the integration of some group-buying companies in new communities, or the integration of online and offline, so as to quickly establish a scale threshold. Currently, most offline supermarket chains are starting to do community group-buying business, but this is just a means to expand profits.
With the entry of new capital, the market space of local community group buying will be enhanced, but the share of small capital enterprises will also be reduced.

On the one hand, the intensive order demand and distribution reduces the cost of product fulfillment, and community group buying has the hope to become one of the mainstream channels for household consumption (the market generally judges the proportion to be at $30 \%$ ); on the other hand, the traffic dividend of online communities also allows community group buying enterprises around the world to show explosive growth, the popularity of WeChat and WeChat payment, the optimization of small programs for shopping and payment experience, the threshold of community group buying The threshold for community group buying is not high, and the profitability is basically verified. It is a fact that community group buying is becoming the bag of giants, and the next stage will be the life and death of community group buying brands. Small and medium-sized community group buying players in the fight to develop the user's consumption habits, but it is likely to eventually clean up the battlefield to harvest the fruits of victory is still Ali, Meituan, Jindo and other giants.

\subsection{Developments of the Issue}

As an e-commerce model residing on WeChat's ecology, community group buying relies heavily on WeChat's official policies and WeChat users' usage habits and user stickiness, bringing various potential uncertainty risks to the future sustainable and stable development of community group buying companies. As e-commerce channels continue to sink into third- and fourth-tier cities and communities, goods and services are getting closer and closer to users. And community stores and community group buying happen to have the advantage of being close to users, and community stores and community group buying will have good room for growth in the future. In addition, the community group buying business model has partially been proven, more and more competitors will enter one after another, these competitors include online e-commerce companies, offline retail groups, large supply chain companies, etc., and their online operational capabilities, supply chain management, capital strength and other aspects of the ability will be better than most players in the current community group buying. Based on the balanced consideration of consumer experience and efficiency cost, the possible future 
retail channel is the model of combining online and offline stores and warehouses. In a place close enough to the user, both offline stores can be experienced and goods and services can be quickly delivered to the home through a nearby warehouse. This model takes into account both user experience and supply-side efficiency costs. In the future, certain community group purchase enterprises may try to open offline stores and cooperate with unmanned convenience stores, or even try to forward warehouse + same-day delivery + inventory. 2019 China's community group purchase market size of 34 billion yuan, in 2020 under the stimulation of the epidemic, the community group purchase market is developing rapidly, the market size is expected to double is expected to reach 72 billion yuan, by 2022 China's community group purchase market size is expected to exceed 100 billion. The community group-buying market continues to sink, while achieving a high degree of user education by virtue of convenient access to services.

\section{RESEARCH FEATURES AND INNOVATION POINTS}

\subsection{Research Features}

Community group purchase is issued between the second and third-tier cities, it is different from traditional e-commerce, using the pre-purchase + pick-up model, and gradually penetrating into the townships and rural areas. It is understood that Xingsheng Yousei in Hunan, more than $60 \%$ of the orders come from the rural areas of townships and below. After experiencing the penetration of Taobao, Jingdong and Jindo's e-commerce, community group buying has further opened up the rural market with cheaper prices and more efficient fulfillment. The rapid development of community group buying, so that the major enterprises are no longer limited to the communities of large cities, but gradually expanded to some rural areas on the edge of the city, began to pay attention to the layout and development of the sinking market, which also fully illustrates the competitiveness of community group buying in the domestic market is expanding, community group buying and the integration of new rural areas have the following advantages.

\subsubsection{Feature 1: Applicable Model and High Efficiency of Promotion}

Rural areas with village residence analogous to urban neighborhoods can be applied with this model. The Internet is not popular in some rural areas, and rural residents are not used to highintensity Internet access. Therefore, the most common way of communication between neighbors is to get together directly to chat and exchange some new things. The simplest communication is the most primitive and effective. With the emergence of community group buying, as long as a few people use it first, and then promote it through this kind of communication between neighbors, it can drive the whole village at once. We only need to take a small part of the funds for the villagers to send benefits, and you can reap a great advertising effect.

\subsubsection{Feature 2: Scattered Villages and Large Labor Force}

Villages are scattered, but the distance is not very far, large logistics companies can not sink to the village delivery. We cooperate with logistics companies and recruit local people to operate our new logistics. Local people know more about village routes and local habits, which not only improves the trust of villagers, but on the other hand, keeps the young people in the village to develop in the countryside, and to some extent alleviates the social problems of children left behind as widows and orphans.

\subsubsection{Feature 3: Expanding User Market and Increasing Consumption Level}

Nowadays, with the accelerating pace of urbanization, the consumption level of rural residents has been effectively improved, and there are centralized markets for residents to consume and shop, so that the rural market comes into being, and it becomes possible to carry out rural community group buying. This pre-sale + group purchase method can effectively activate the consumption demand of rural consumers, so that the community group purchase and the new logistics model can be well developed, at the same time to a certain extent to promote, the development of rural local.

\subsection{Innovation Points}

It has the following innovation points:

- Build a new rural logistics ecosystem model of "community group purchase and new rural eco-logistics double-layer circle". This model is a new rural logistics 
ecosystem consisting of "chain-loopfunction" and "platform-module".

- To reveal the mechanism, path and direction of the ecological evolution of new rural logistics. The evolutionary mechanism of "integration-synergy" is the new development direction of integrating community group purchasing into new rural logistics.

- It is an important management inspiration that "two-way — double network - twolayer platform" is an evolutionary model of urban-rural integrated logistics ecosystem. The top-level virtual platform of urbanization and the physical logistics platform of village-based logistics are no longer separated, forming a new rural logistics and community group purchase integration model of "two-way — double network - two-layer platform".

\section{TECHNICAL ROUTE}

This paper intends to realize this innovation model study through the following technical route.

In this paper, by using the improved three-stage DEA-Malmquist index method to process the inputoutput data of new rural logistics service nodes from 2012 to 2021 , and by evaluating the efficiency of "chain-loop-function", it is concluded that after 2012, due to the burst of Internet technology, the formation of The "platform-module"-led bilateral market of e-commerce has shifted the operational efficiency of new rural logistics service providers from dispersion to convergence.

This paper uses evolutionary game theory combined with the revenue matrix and replication dynamic equation to analyze the cooperation mechanism between the operating body of village e-commerce platform, the platform using body and the government, and the technological innovation with the Internet as the core is the important support of the "platform-module" development mode, and the network platform also promotes the urban and rural logistics The same conclusion was reached after the simulation using MATLAB.

This paper constructs the internal renewal fractal mechanism of the new rural logistics ecosystem based on non-equilibrium mechanics, and quantifies and analyzes through the theoretical model that "eco-logistics" has fractal influence on the spatial and temporal structure of the new rural logistics ecosystem, and the change of spatial structure of the new rural logistics is the basis of the evolution of the new rural logistics ecosystem, and the internal The spatial variation of the role of "eco-logistics" is the essence of system evolution.

This paper uses SOM neural network simulation to predict the role of "eco-logistics" and finds that the spatial self-organization of the new rural logistics ecosystem grows slowly under the stable external environment, and after 2012, under the impetus of urbanization policy, the spatial environment of new rural logistics changes dramatically and enters into a new dimension of spatial reconstruction and scale growth, so that the whole The evolutionary process has typical leapfrogging, but the expansion of logistics scale still lags behind the expansion of the built-up area of villages and towns.

Based on the historical data and development forecast from 2006 to 2026, this paper extrapolates and predicts the interaction scenarios through the new rural logistics environment subsystem.

The current stage of completion includes the creation of WeChat public number; the operation of WeChat public number; and the background management of WeChat public number. WeChat public number operation process includes, first of all, public number positioning, name, avatar, public number name, public number avatar, next is the public number layout, home page introduction words, menu bar settings, and finally is the attraction, third party platform attraction, their own fission growth, and high price purchase. The profit methods of public accounts include advertising, traffic owners, appreciation, and high-quality community. The background management of WeChat public number completes three modules: material management, message management and user management core positioning (target positioning, function positioning, crowd positioning)

\section{RESEARCH FINDINGS}

\subsection{Weak Acceptance of the Integration of Community Group Buying and New Rural Logistics, Unclear Market Demand and Insufficient Supply Chain Capacity}

The logistics awareness in rural areas is weak, and the traditional concept of the majority of farmers is still dominant, they are more willing to go to buy in person than the combination of new rural logistics and community group purchase, and 
the traditional concept leads to the emergence of new logistics is not trusted.

With the combination of both, we need to grasp the needs of the rural market, choose the products they need, and need to understand the needs of the rural market; rural consumers prefer much more to such products, and fully cater to consumer preferences, in order to maximize the advantages of the combination of new rural logistics and community group buying. Network platform construction is still facing all kinds of problems. In this process, how to ensure the quality and the efficiency of logistics is also critical. And to ensure continued good products, categories and logistics, it is necessary to consider enough selection of operations staff. Due to the high efficiency of traffic acquisition, light model, and easy to copy expansion, community group buying model soon blossomed all over the country. However, as competition intensifies, the industry gradually fell into a money grabbing point, grabbing "head" of the money burning war, and the original cost advantage no longer exists. At the same time, the problem of insufficient supply chain capacity of the entrepreneurial platform is also becoming more and more prominent.

\subsection{Excessive Reliance on the Head of the Platform, Low Profit and Low Cost}

As a group buying channel, in the context of fierce enough competition, we should constantly improve the after-sales service protection system to protect the rights and interests of consumers. Logistics still has various problems, indirectly affecting the proportion of costs and profits. Once the category is increased, it means that the logistics and supply chain costs increase, which means that the logistics and supply chain costs rise rapidly. Moreover, the new warehouse with enough density, close enough to the user and fast enough delivery, again means a rapid rise in various costs.

\subsection{Too Much Reliance on WeChat and WeChat's User Habits and User Stickiness}

As an e-commerce model residing on WeChat's ecology, community group buying is very dependent on the official policies of WeChat and WeChat's user habits and user stickiness, which brings potential uncertainty risk to the sustainable and stable development of community group buying companies in the future. Although WeChat has a wide variety of platforms, it is easy to make people feel aesthetic tired or interfere with users. The model uses the Internet as a platform, but in rural areas, the Internet is not very popular, and the promotion of online platforms has become a problem, and it is a huge challenge to get people to accept online platforms.

\section{COPING STRATEGIES}

Firstly, it is necessary to actively publicize to rural areas to introduce new consumption ideas to rural areas. Community group purchase adopts the three-level warehouse to reduce the supply risk and commodity damage risk. We will make multi-party comparisons. We will go deeper into the rural market, understand the needs of farmers, and choose the products that fully meet the rural market and are loved by rural residents, so as to maximize the advantages of combining new rural logistics and community group purchase. It is decided that the selection of community group purchase should be based on high-frequency household consumer goods, with daily food and clothing items being the key selection targets, and fruits, vegetables and fresh produce being daily necessities, with emphasis on the repurchase rate. On the basis of price advantage, we also need to ensure the quality of supply and form a good reputation. Group buying platforms continue to innovate and expand their business scope to provide consumers with sufficient products. Gradually, we will improve the supply chain. The second group purchase platform can be operated through a clear responsibility. This will not reduce the consumer's desire to buy. This pain point is especially obvious for those community group buying platforms that use ecommerce reworked community group buying systems and solitaire-type applet tools. Because the order process of this type of system, in the process of pushing it to consumers, there may be a leader for profit. The mall applet is divorced from the leader's applet, and the leader uses the independent applet to follow up orders, while the platform can reach consumers directly through the mall applet and obtain user data. The head of the group only plays the role of notifying the new products and opening of the group in the WeChat group.

At the same time, the system also provides single product poster function, which can generate an exclusive QR code for a single product, which can be used for printing ground marketing materials or friends marketing. Consumers can scan the QR code of a single product and enter the product detail 
page of the small program directly, skipping the head of the link and ensuring the marketing effect for the platform.

We can keep customers and capture traffic by seckilling or regular activities. Whether the business ability of the community group purchase leader is excellent, is also an important factor in whether the community group purchase can be profitable, to constantly cultivate your own operational ability. Third, it is necessary to improve the platform management. To promote rural community group buying, we need to do a good job of promoting and letting rural consumers know about this model. In rural areas, local habits can be adopted to promote the model. Rural community group buying also needs to provide high-quality goods, but choose it precisely so as to fully meet consumer preferences, more easily to obtain the trust of users. Efforts should be made to look for the rural collection points as the extraction points.

\section{CONCLUSION}

This study has enabled students to conduct innovative developmental research in logistics through interdisciplinary training of college students. The students and faculty practiced the process of establishing the integration model of community group purchasing and new rural logistics through the establishment of a public platform of WeChat. The research in this paper takes necessities as the main selection, establishes an efficient community group-buying system, and uses a three-tier logistics system of [city/county warehouse] — [street/township station] [community/village store] to ensure transportation quality and efficiency. At the same time, students and teachers look for rural residents more concentrated points as extraction points, and the government has a policy of support for innovation and entrepreneurship. In order to seek government policy help and cooperate with relevant companies to promote (promotion focuses on the ground promotion model), the authors divorced the mall applet and the head end applet. The head of the group only plays the role of notifying the new and opening of the products in the WeChat group to reduce its dependence on the head of the group. The research in this paper has resulted in the following findings.

First, this paper has made a detailed analysis of the feasibility of the new rural logistics ecosystem model of "community group purchase and new rural eco-logistics double-layer circle" through investigation and research, and has conducted a research on the current situation of rural logistics. The project leader submitted a paper "A study on the current situation of community group buying in new rural logistics based on mobile network" in EI international journal. A study on the current situation of community group buying in new rural logistics is based on mobile networks", which was submitted at the end of 2020, and has been revised twice and entered the third review, and has received an acceptance notice, and will be published and retrieved in November 2021.

Second, through many communications with the villagers and village committee leaders, we have now obtained a written consent from the village committee of Luoqiao Town along the street in Funing County to allow the establishment of a community group purchasing service point from the activity center. We also drafted a contract with Changchun Hengrong Logistics Co Ltd, a subsidiary of Axon US Corp, an online e-commerce company based in New York, USA. The head office was established in 2006 in New York, USA, and has branch offices in London, UK and Changchun, China. The company strongly supports the ecological model project of community group buying and new rural logistics proposed in this study, and also actively funds this paper for college students to start their own business, and a cooperation agreement will be drafted at the end of 2020. Tentatively, a school-enterprise cooperation agreement will be signed with the College of Foreign Languages of Changchun University of Engineering on May 24, 2021. The model has also received capital injection.

Third, through the contact of the faculty and the supervisor, two external experts have now been invited to provide theoretical guidance and technical support to this paper. The first expert is Professor Du Li from the Department of Finance of Jilin University, supervisor of doctoral students. He is the chief expert of the major project of the National Social Science Foundation of China (NSFC) and the leader of the key project of NSFC, "Research on financial mechanism and system in the era of low-carbon economy". He has been awarded the special allowance by the State Council Government, the Baogang Foundation Outstanding Teacher Award, the first batch of top innovative talents in Jilin Province, the senior expert of Jilin Province, and the special professor of Jilin University, Kuang Yaming. Another expert is Changchun Institute of Optics and Mechanics directly under Chinese Academy of Sciences, 
Director of Big Data Research Center, researcher Duan Xiaozheng. This paper also has the honor to get the support from KDDI Changchun Branch and Chaoyang Xunfei AI Double Innovation Base, whose suggestions and support to the platform technology make the formation of the new rural logistics ecosystem model of "community group purchase and new rural eco-logistics double layer circle", and the construction of two-way - double network - double layer platform possible.

\section{AUTHORS' CONTRIBUTIONS}

Rouhua Wang was responsible for writing the thesis, and Jiali Zhu was responsible for project implementation and text proofreading.

\section{REFERENCES}

[1] B ask A, Lipponen M, Raj ahonka M, et al. Framework for Modularity and Customization: Service Perspective [J]. Business and Industrial Marketing, 2011, 26(5):306-319.

[2] Voss C A, Hsuan J. Service Architecture and Modularity [J].Decision Sciences, 2009, 40(3):541-569.

[3] Asan U, Se \}kin Polat, Serdar S. An Integrated Method for Designing Modular Products [J]. Journal of Manufacturing Technology Management, 2004, 15(1):29-49.

[4] Meyer M H, Lehnerd A P. The Power of Product Platforms [M]. New York: The Free Pres, 1997.

[5] Mikkola J H. Management of Product Architecture Modularity for Mass Customization: Modeling and Theoretical Considerations [J]. IEEE Transactions on Engineering Management, 2007, 54(1):57-69.

[6] Gawer A, Henderson R M. Platform Owner Entry and Innovation in Complementary Markets: Evidence from Intel [J]. Economics and Management Strategy, 2007, 16(1):1-34.

[7] Economides N, Katsamakas E. Two-sided Competition of Proprietary vs. Open Source Technology Platforms and the Implications for the Software Industry[J].Management Science, 2006, 52(7):1057-1071.

[8] Thierry I, Lescop D. Strategizing in Platformbased Ecosystems: Leveraging Core Processes for Continuous Innovation [J].
Communications \& Strategies, 2015,(99):91111. 